\title{
Evaluating the change in Streptococcus mutans in plaque around orthodontic brackets using fluoride toothpaste, probiotic curd, and recaldent - A comparative in-vivo study
}

\author{
Mueez Bashir, Shedam*; Ajit, Kalia*; Ashwith, Hegde*; Nasim, Mirdehghan*; Burhanuddin Kutub, Malpurwala* \\ * M.A Rangoonwala College of Dental Sciences and Research Centre, Department Of Orthodontics and Dentofacial Orthopaedics, Pune, India
}

\begin{abstract}
Introduction: Enamel demineralization is still a problem associated with orthodontic treatment, leading to the formation of white spot lesions; this is a grave concern to orthodontists and patients. Various methods are now employed to reduce the incidences of demineralization.

Aim: To evaluate and compare the effects of Fluoride toothpaste, Probiotic curd, and Recaldent on Streptococcus mutans colonies in plaque around orthodontic brackets in different groups of patients. Further, the three agents were compared and assessed for regular use by orthodontic patients for reduction of decalcification.

Materials and methods: This study consisted of 60 randomly selected patients having orthodontic treatment in the Department of orthodontics and dentofacial orthopaedics. The study protocol was approved by the institutional Ethics committee of MCE Society, Azam Campus, Pune. Group A: The patients were given fluoride containing toothpaste (ParodontaxTM Daily Fluoride toothpaste GlaxoSmithKline). Group B: The patients were asked to brush twice daily with recaldent containing tooth mousse (Dentsply Tooth Mousse- GC). Group C: Patients were given probiotic curd(Nestle Acti Plus). Samples were collected twice, once initially, seven days after bonding at the start of the study and secondly, after 30 days. After DNA extraction PCR analysis was done to evaluate the colonies of S. mutans as colony forming units per milliliter $(\mathrm{CFU} / \mathrm{ml})$ in the plaque specimens. RealPlex software programme was used to plot the results of the colonies detected in the sample.

Results: Streptococcus mutans colonies around the brackets after 30 days post use of Fluoride toothpaste, probiotic curd and Recaldent was reduced by $44.5 \%, 0.86 \%$ and $41.8 \%$ respectively.

Conclusion: The regular use of fluoride toothpaste and Recaldent will help in reducing decalcification during orthodontic treatment. Further research is needed to establish the advantages of probiotic curd in reducing white spot lesions.
\end{abstract}

Shedam MB, Kalia A,Hegde A, Mirdehghan N, Malpurwala BK. Evaluating the change in Streptococcus mutans in plaque around orthodontic brackets using fluoride toothpaste, probiotic curd, and recaldent - A comparative in-vivo study

South Eur J Orthod Dentofac Res. 2018;5(1):12-18.

Submitted: October 7, 2018; Revised: March 25, 2019; Published: April 30, 2019

\section{INTRODUCTION}

Orthodontic advancements have enhanced the quality of various modalities of treatment thereby improving standards of treatment drastically. However, enamel demineralization following treatment, leading to white spot lesions, continues to

\section{Corresponding Author:}

Burhanuddin Kutub Malpurwala

M.A Rangoonwala College of Dental Sciences and Research Centre,

Department Of Orthodontics and Dentofacial Orthopaedics,

Pune, India

e-mail: burhankutubm@gmail.com be a severe issue for practitioners as well as patients.

The presence of fixed orthodontic appliances hinders oral hygiene maintenance and increases the plaque retentive areas. ${ }^{1}$ Consequently, the lower $\mathrm{pH}$ of the accumulated plaque on the enamel surface near the brackets hampers the remineralization process and decalcification occurs. ${ }^{2}$ White spot lesions are common around the cervical region of molar bands, and the lateral incisors in both arches, followed by the cuspids. ${ }^{3}$ The presence of white spots among orthodontic patients is said to be between $4.9 \%$ and $84 \% .^{3}$

Various methods are stated to either stop this process of decalcification or to reverse the damage. Fluoride application, ${ }^{4}$ 
casein phosphopeptide-amorphous calcium phosphate (CPPACP), ${ }^{3}$ and use of argon laser ${ }^{5}$ have proved to be advantageous. The steady release of fluoride from sealants and other bonding materials, like primers/adhesives, can also be of use.

Biological methods (antibiotics, antimicrobial therapy with chlorhexidine, povidone iodine, and penicillin) have also become prominent, but antibiotic treatment must be given regularly for effective long-term results. ${ }^{6}$

Probiotics have recently been introduced as an alternative. They act by competitively inhibiting the pathogenic bacteria because they have higher adhesion to the tissues. They inhibit pathogens but do not inhibit friendly bacteria. ${ }^{7}$

Probiotics are a part of the diet in the form of fermented foods, or as dietary supplements with added active live cultures. Their usefulness on oral health by eliminating gingivitis, halitosis, ${ }^{8,9}$ and caries ${ }^{10,11}$ has been proved, and thus probiotics are now included in mouthwashes and dentifrices. Some studies have shown that Streptococcus mutans in saliva have decreased after probiotic use. ${ }^{10}$ However, there are not many studies evaluating the effects of probiotics in orthodontic patients, since their use in orthodontics is still at an early stage. ${ }^{10}$

Several methods have been employed to identify Streptococcus mutans, including colony morphology on mitis salivarius agar, biochemical tests and immunological methods. These techniques are time-consuming and therefore are not useful in situations where rapid decision making is necessary. Molecular approaches were, hence, introduced for quick detection and identification of mutans streptococci in oral samples. Polymerase chain reaction (PCR) offers a more sensitive and specific means of detection for bacteria than conventional means. ${ }^{12,13}$

Since there are few studies comparing different agents to reduce white spot lesions, we aimed to evaluate and compare the effect of Fluoride toothpaste, Probiotic curd, and Recaldent on Streptococcus mutans colonies in plaque around orthodontic brackets in different groups of patients. Further, we compared each of these agents and ruled out if any of these agents could be used regularly on orthodontic patients for reduction of decalcification.

\section{MATERIALS AND METHODS}

This study was a double-blinded and randomized trial, consisting of 60 randomly selected patients having orthodontic treatment in the Department of orthodontics and dentofacial orthopaedics. The study protocol was approved by the institutional Ethics committee of MCE Society, Azam Campus, Pune.

\section{Inclusion criteria}

1. Age between 14 and 30 years

2. Patients undergoing fixed orthodontic therapy.

3. Patients with all permanent dentition

4. Patients with good general health (no significant medical history or drug use during the last month),

5. Patients with a habit of brushing twice daily with toothpaste.

\section{Exclusion criteria:}

1. Patients with use of anti-inflammatory or antibiotic medications taken in the month before the study.

2. Patients with the use of chewing gum or mouthwash used in the last week and during the study.

3. Patients with the habit of smoking/alcohol/tobacco.

4. Patients with pre-existing gum diseases.

\section{Materials Used:}

1. Sterilized Straight probel scaler for plaque collection (Figure 1)

2. Sterile polycarbonate vials for plaque collection (Figure 2)

3. Parodontax Daily Fluoride toothpaste GlaxoSmithKline -1400 ppm (Figure 3)

4. Nestle Acti Plus probiotic curd. (Figure 4)

5. Dentsply Tooth Mousse - GC (Figure 5)

6. Micropipettes tubes for DNA isolation. (Figure 6)

7. BioBeeTM Centrifuge machine (Figure 7)

8. BIO RAD Vortex machine for DNA extraction (Figure 8)

9. KEMI Water Bath (Figure 9)

10. Real-time PCR machine - Thermal cycler: Master cycler, Eppendorf, Germany (Figure 10)

11. PCR Reagent (Master mix): Roche.

12. LABLINE Biological safety cabinet (Figure 11)

13. Oligonucleotide Primers: Bioserve India pvt Ltd Streptococcus mutans primers - (Figure 12)

GTFB - F5' - ACTACACTTTCGGGTGGCTTGG -3' GTFB - R5' - CAGTATAAGCGCCAGTTTCATC -3'
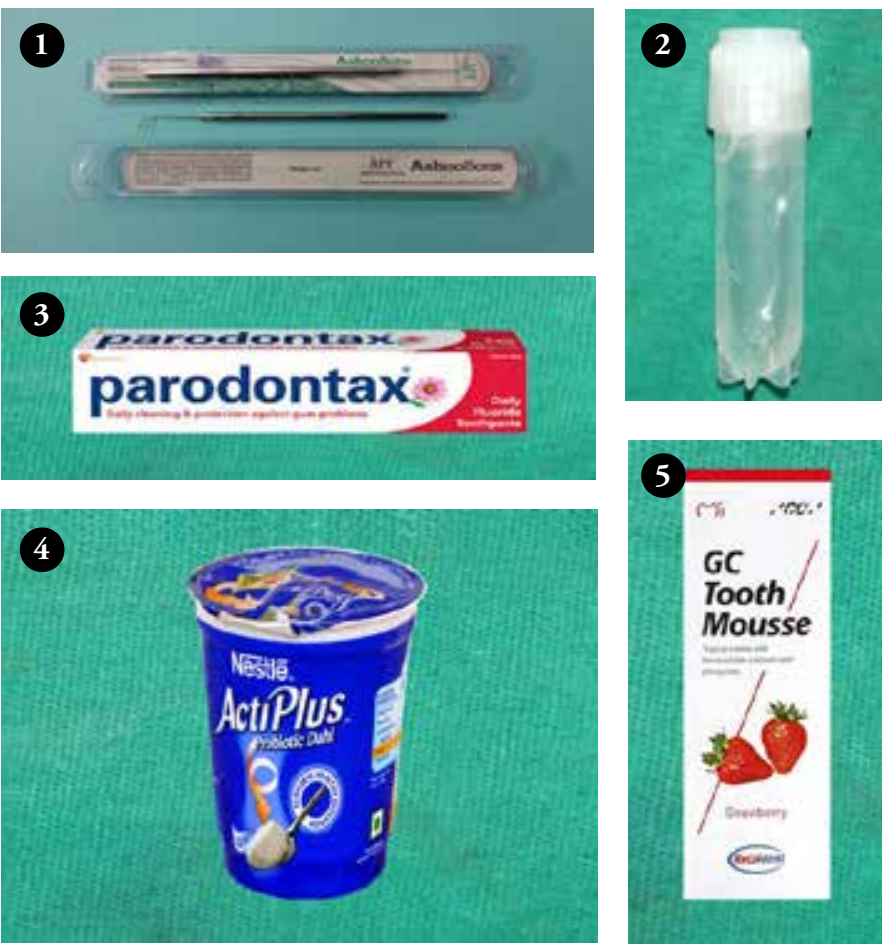

Figures 1 - 5 . 

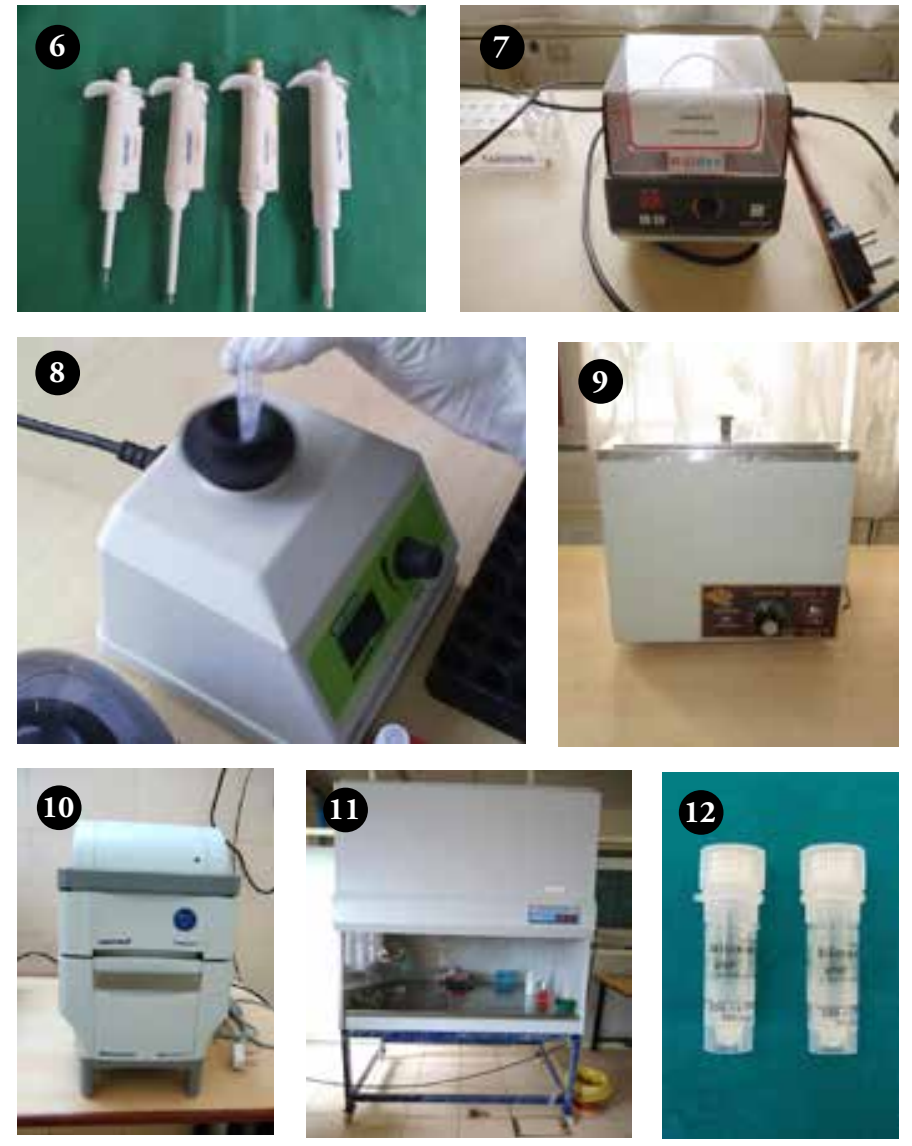

Figures 6 - 12.

Group A: The patients were given fluoride containing toothpaste (Parodontax Daily Fluoride toothpaste GlaxoSmithKline) and asked to brush twice daily.

Group B: The patients were asked to brush twice daily with Recaldent containing tooth mousse (Dentsply Tooth Mousse-GC). Group C: Patients were given probiotic curd (Nestle Acti Plus) to eat daily after lunch and maintain regular brushing habits.

All patients were instructed to follow proper oral hygiene measures.

\section{Method:}

\section{Step 1:}

Sample collection: Samples were collected twice, once initially, seven days after bonding at the start of the study and secondly, after 30 days.

1. Scaling and polishing were done before bonding.

2. After bonding patients were instructed oral hygiene procedures and first plaque specimens were collected after seven days from the labial surfaces immediately surrounding the orthodontic brackets of the maxillary lateral incisors using a 4-pass technique. (Figure 13)

3. After collection of initial sample patients received Fluoride toothpaste, Probiotic curd, Tooth mousse as per their group.

4. Patients in the fluoride group and Tooth mousse groups were instructed to brush twice daily and discontinue their regular toothpaste.
5. The patients were asked to follow Bass Technique of Toothbrushing.

6. Patients in the probiotic curd group were instructed to eat curd daily once post lunch and follow routine oral hygiene procedures.

7. Patients were instructed to strictly follow this daily for one month and fill up the daily use compliance document given to them which was collected post 30 days for assessment (Figure 14a, 14b and 14c).

8. The patients were also instructed to avoid chewing gums, mouthwashes, and antibiotics during the study.

9. Plaque specimens were collected in vial tubes and coding was done serially based on the group and sealed for transport for DNA isolation to Department of Molecular Biology and Immunology. (Figure 15)

10. The coding of the specimens was not disclosed to the laboratory personnel and helped to minimize experimental bias.

11. After completion of one month, patients were recalled and plaque specimen was collected again using the same procedure.

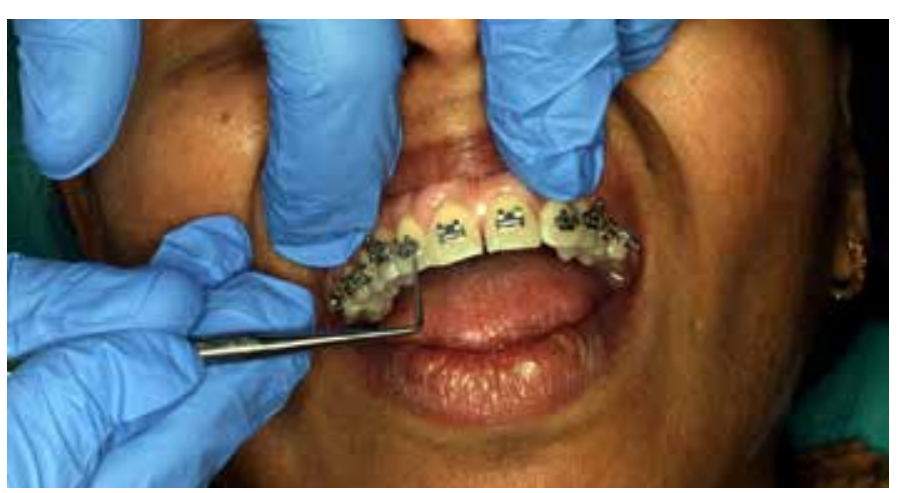

Figure 13.

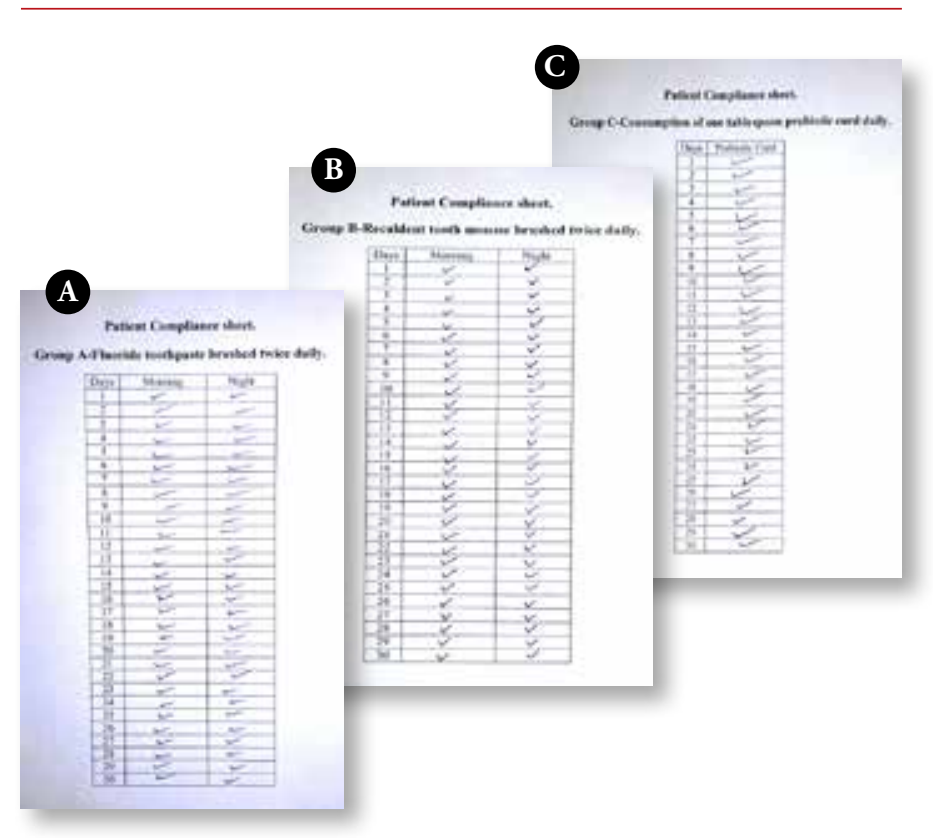

Figures $14 a, 14 b, 14 c$. 


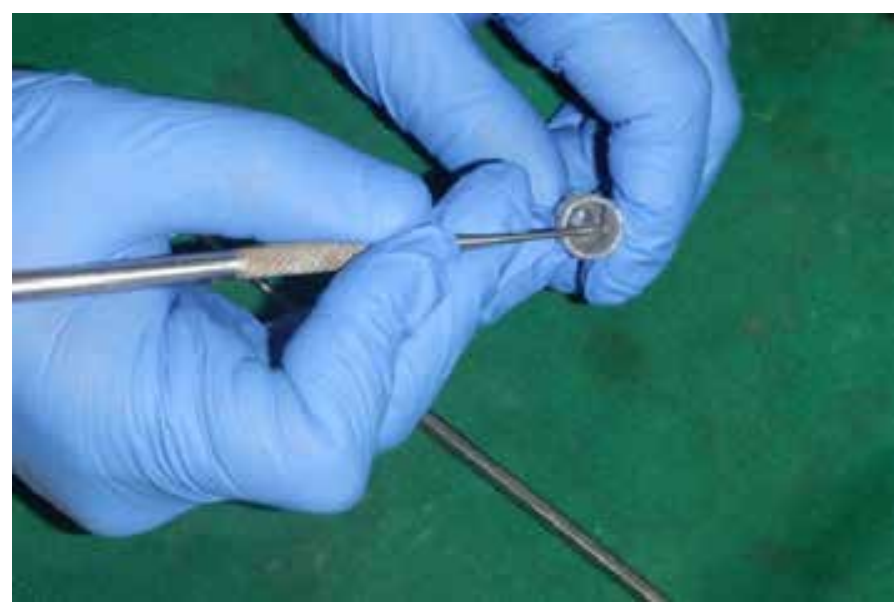

Figure 15.

Step 2: DNA Extraction Procedure (Modified Proteinase-K method) ${ }^{14}$

\section{A. Buffers used-TE Buffer; Lysis Buffer I, Lysis Buffer II. (Figure 16)}

\section{B. Procedure:}

1) Transfer the sample to the tube containing T.E.buffer.

2) Centrifuge at $5,000 \mathrm{rpm}$ for $5 \mathrm{~min}$.

3) Discard the supernatant. Add 500 microliter fresh T.E. buffer centrifuge for 3-4 minutes

4) Repeat the above procedure for 3-4 time with fresh T.E. buffer.

5) Discard supernatant add 50 microliter lysis buffer I, Vortex it and keep for $5 \mathrm{~min}$,

6) Add 50 microlitre Lysis buffer II and 10 microliter proteinase - K (100 ug/ml), vortex vigorously. Keep it in a water bath for $2 \mathrm{hrs}$ then keep in boiling water bath for 10 minutes.

7) Stored the DNA at -200C.

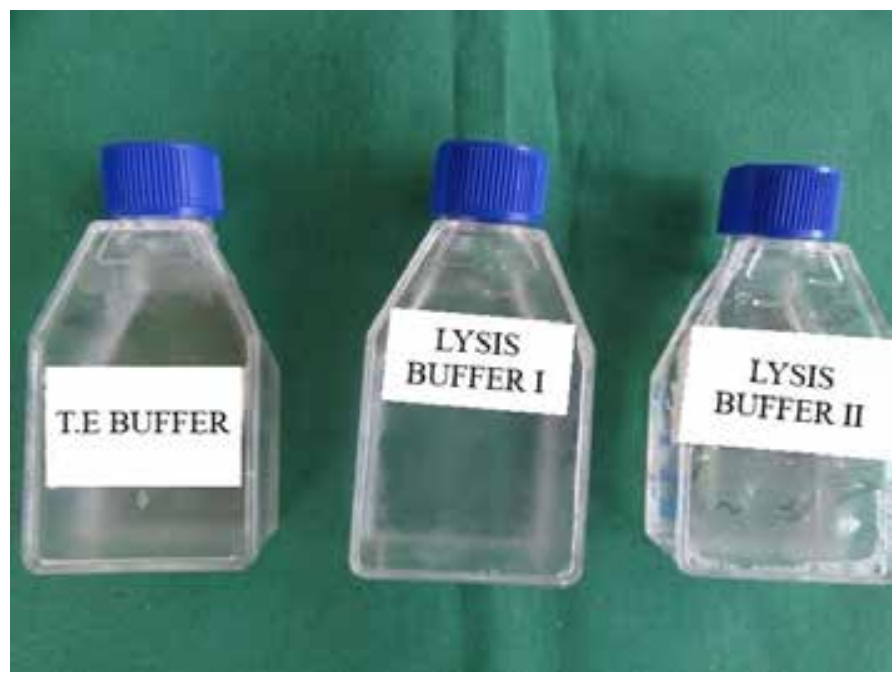

Figure 16.

\section{Step 3: PCR Procedure}

A premixture was prepared and aliquoted into each tube. The premix contains the following components in a final volume of $20 \mu \mathrm{l} /$ aliquot.

FastStart Universal SYBRgreen master mix $: 10 \mu \mathrm{l}$

P. intermedia( Forward primer) $\quad: 1.5 \mu \mathrm{l}(15$ pmole $)$

P. intermedia(Reverse primer) $\quad: 1.5 \mu \mathrm{l}(15$ pmole $)$

Template DNA

Water

$: 3 \mu \mathrm{l}(<1 \mu \mathrm{g} /$ reaction $)$

: Added to make final volume to $20 \mu \mathrm{l}$

(Roche Fast Start Universal SYBR green PCR master mix was used which contain $2.5 \mathrm{mM} \mathrm{Mgcl} 2$. In addition, the master mix contains Taq polymerase enzyme, dNTP mix, and Syber green dye) The SYBR Green dye is a fluorescent intercalating dye which binds with double-stranded DNAs which were specifically amplified by Streptococcus mutans specific primers. Upon its excitation $(498 \mathrm{~nm})$, it emits light $(522 \mathrm{~nm})$ that can be recorded by Realplex software of the thermal cycler. Serial dilutions of DNA extracted from standard strain of Streptococcus mutans (ATCC No 25175) was prepared and run simultaneously with the test samples. The graph was plotted as the amount of fluorescence against the number of cycles. A standard curve was obtained by the Realplex software. The amount of amplified DNA in the samples was obtained from the standard curve and was measured in colony forming unit per milliliter.

\section{Statistical Analysis:}

The results obtained were further subjected to statistical analysis for evaluation of Streptococcus mutans count at baseline (T0) and 30 days (T1) post use of products for all three study groups. Both inter-group and intra-group comparison was also evaluated for statistical significance. Statistical analysis was performed using one-way analysis of variance (ANOVA) with post-hoc Bonferroni's test for multiple group comparisons.

\section{RESULTS}

\section{Inter-Group Comparison of Cell Count-T0 (Figure 17)}

- Seven days after the placement of brackets, the plaque sample was collected from all three study groups as a control baseline values (T0). The average baseline cell count did not differ significantly across three study groups ( $\mathrm{P}$-value $>0.05$ for all).

\section{Inter-Group Comparison of Cell Count-T1 (Figure 18)}

1. 30 days after placement of brackets and post use of fluoride, Recaldent and probiotic curd, plaque sample was collected from all three study groups and was labeled as T1.

2. The average 30 days cell count did not differ significantly across three study groups (P-value $>0.05$ for all).

3 . The average $\%$ change in cell count at 30 days did not differ significantly between Group A and Group B (P-value>0.05). 
4. The average $\%$ change in cell count at 30 days is significantly higher in Groups A and B compared to Group C (P-value $<0.01$ for both).

Intra-Group Comparison of Cell Count-T0 and T1 (Figure 19)

1. In Group A, The average baseline cell count is significantly higher compared to the cell count after 1-month (P-value $<0.05)$.

2. In Group B, The average baseline cell count is significantly higher compared to the cell count after 1-month (P-value $<0.05)$.

3. In Group C, The average baseline cell count did

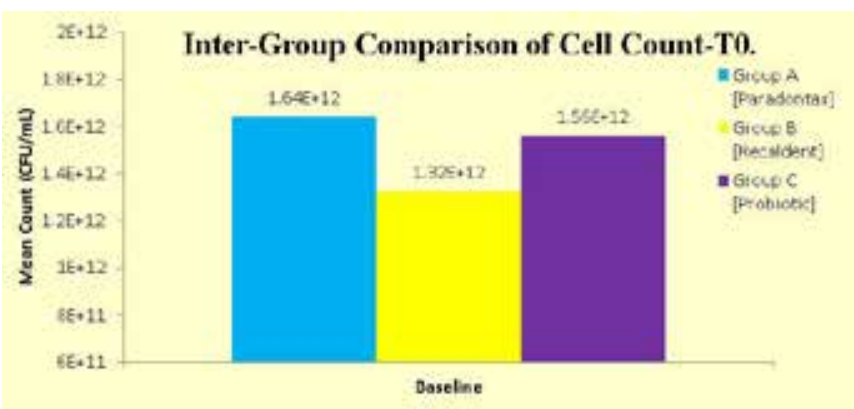

Figure 17.

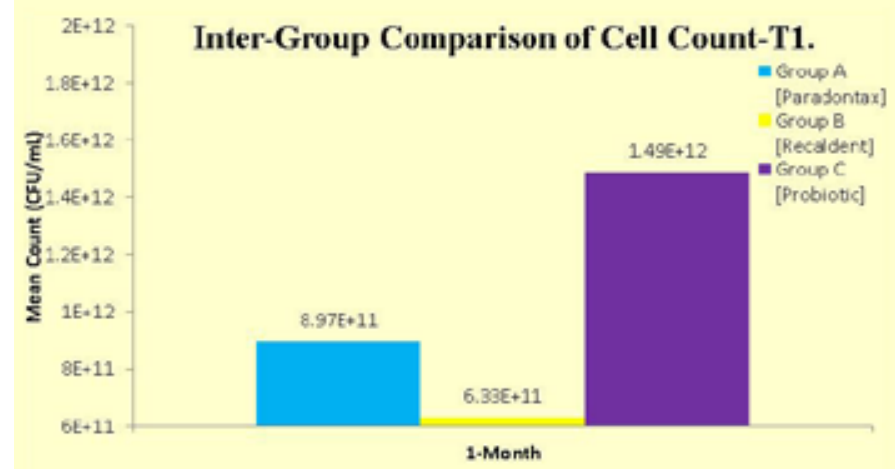

Figure 18.

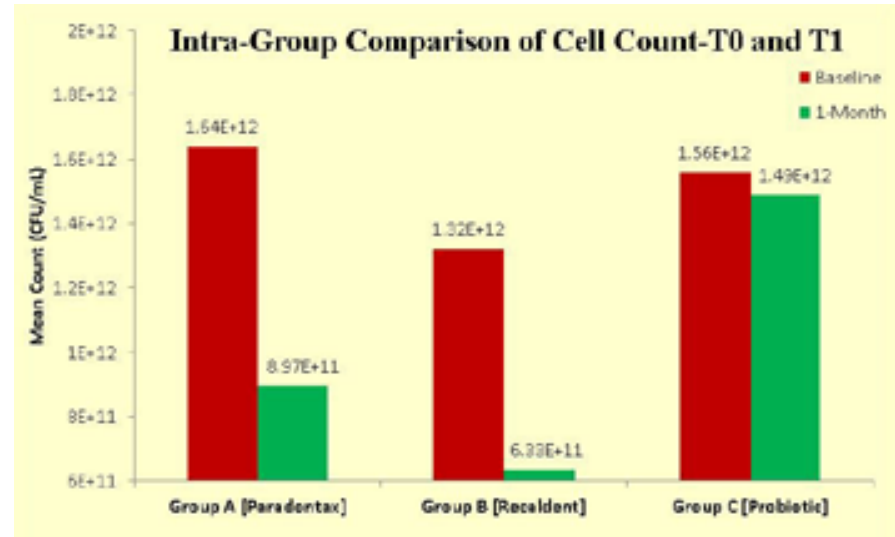

Figure 19.

\section{DISCUSSION}

As reported earlier, enamel demineralization is a common occurrence after fixed mechanotherapy ${ }^{15}$ and is prominent in patients with poor oral hygiene. It is mainly caused by the organic acids produced by cariogenic microbes in the oral environment.

Streptococcus mutans play a role in the initiation of tooth decay. Inhibiting their accumulation on the surfaces of teeth stops biofilm development and in effect, prevent dental caries. ${ }^{16}$ They are also the most cariogenic because of their stronger adhesion and release of acid. ${ }^{3,17}$ Thus, we assessed colonies of Streptococcus mutans for our study.

According to Gorelick et al., lateral incisors are the most affected because of reduced salivary clearance and less space between brackets and gingivae. Geiger et al., stated that lesions occurred most frequently on maxillary lateral incisors and cuspids. ${ }^{18}$ Thus, considering these studies, we decided to collect plaque specimens from maxillary lateral incisors as they are more susceptible to WSLs.

Streptococcus mutans in the saliva is not ideal as it includes the total number of the organisms in the oral environment, not just the tooth surface. Some studies have observed differences between the salivary Streptococcus mutans counts and the Streptococcus mutans counts in plaque ${ }^{19,20}$. Based on this, it was justified to use the plaque sample for evaluating the count of the Streptococcus mutans more accurately.

Fluoride is considered the most effectual cariostatic agent in dentistry. ${ }^{21}$ Acid phosphatase from Streptococcus mutans is thought to play a role in the release of phosphate from the enamel matrix during demineralization. ${ }^{22}$ Fluoride is a potent inhibitor of acid phosphatase at acidic $\mathrm{pH}$ values and this, coupled with the F-induced efflux of phosphate from the cell, is thought to promote enamel remineralization. ${ }^{23}$ Thus, in the present study, Group A was given fluoridated toothpaste to be brushed twice daily.

A study reported by Stratemann and Shannon used a stannous fluoride gel. Only $2 \%$ of the subjects using the fluoride gel exhibited decalcification compared with $58 \%$ of the control group. ${ }^{24}$ Another study by Geiger et al. (1992) using a neutral sodium fluoride rinse reported a $25 \%$ reduction in the incidence of white spot lesions. ${ }^{25}$ A reduction of $44.5 \%$ of Streptococcus mutans was achieved in group A of our study, post 30 days from the baseline count. Our results were in accordance with the previous studies conducted which showed similar findings. ${ }^{26,27,28}$ We used Recaldent in our study for group B. As highlighted by Walsh (2009), this is a widely studied compound known as topical tooth creme GC Tooth Mousse ${ }^{\mathrm{TM}} / \mathrm{MI}$ Paste ${ }^{\mathrm{TM}}$. Recaldent works effectively as a remineralizing agent at acidic $\mathrm{pH}$ levels (down to 4.0) as well as in the neutral and alkaline range ${ }^{29,30}$ This complex has gained significance in the field of dentistry for its use in treating conditions like white spot lesions, fluorosis, orthodontic decalcification, enamel demineralization, and sensitive dentine. ${ }^{31}$ 
It has been emphasized that Recaldent may influence the properties and behavior of dental plaque through (1) binding to adhesin molecules on mutans streptococci and thus hindering their entry into dental plaque, (2) increasing plaque calcium ion levels to reduce plaque fermentation; and (3) playing a buffer of protein and phosphate in plaque fluid $\mathrm{pH}$. СРP-ACP incorporated into chewing gum, lozenges and mouthrinses has been shown to remineralize enamel subsurface lesions in numerous human in situ studies. ${ }^{32}$ Based on this review, we decided to use Recaldent Tooth mousse GC in our study. We observed a reduction of $41.8 \%$ of Streptococcus mutans in group B, post 30 days from the baseline count. Similar findings were observed in the earlier studies conducted. ${ }^{33,34}$

The third group in our study was given probiotic curd (Nestle Acti Plus probiotic curd), Group C. According to a WHO/ FAO report (2002), probiotics are 'Live micro-organisms which, when used in adequate amounts, offer a health benefit to the host'.

Their mechanism of action may be production of various antimicrobial substances, organic acids, hydrogen peroxide, carbon peroxide and biosurfactants. They also compete with pathogens for sites of attachment and are involved in the metabolism of substrates. ${ }^{35}$ Probiotics create a biofilm, functioning as a protective lining for oral tissues against diseases by keeping the bacterial pathogens off oral tissues by filling the spaces where the pathogens would otherwise colonize.

The typical probiotic food is yogurt (curd) and daily intake of dairy products seems to be best way to ingest probiotic bacteria. ${ }^{6}$ Unlike milk and milk products, curd being semisolid may be retained in the oral cavity for a more extended period with enhanced beneficial effect. Thus, we used a specially formulated probiotic curd that contains $1010 \mathrm{CFU} / \mathrm{ml}$ of Lactobacillus acidophilus. It was found that in group C, the Streptococcus mutans count was $1.49 \times 1012 \pm 4.69 \times 1011 \mathrm{CFU} / \mathrm{ml}$. (Table 2 and Graph 2). The results are in accordance with other studies which support the use of probiotics against salivary Streptococcus mutans.

However, only a reduction of $0.86 \%$ of Streptococcus mutans in group C, post 30 days from the baseline count was observed. A possible reason for such a less reduction of S.mutans may be the inadequate use of probiotic curd. i.e., only one tablespoon daily after lunch for a short duration (30 days) and a relatively small study population $(n=20)$.

Our aim was not only to evaluate the efficacy of fluoridated toothpaste, Recaldent and probiotic curd alone but also to compare among them to assess the best preventive measure against WSLs. Our findings were equivocal for fluoridated toothpaste and Recaldent when compared to probiotic curd. Thus, it can be hypothesized that if the agents are used together, it will provide a synergistic effect against demineralization. Supporting our view, many such clinical studies of mouth rinses and dentifrices containing CPP-ACP and fluoride have provided interesting insights into the synergy between these. For example, the addition of CPP-ACP to a fluoride mouth rinse increases the incorporation of fluoride into dental plaque biofilm. A dentifrice containing $\mathrm{CPP}-\mathrm{ACP}$ with fluoride provides remineralization which is superior to both CPP-ACP alone and to conventional and high fluoride dentifrices. ${ }^{36}$ This synergy between CPP-ACP and fluoride had been identified in laboratory studies using GC MI paste/Tooth Mousse, which showed that Tooth Mousse (without fluoride) remineralized initial enamel lesions better when applied as a topical coating after the use of a fluoride dentifrice. ${ }^{37}$

There were few limitations in our study which needs to be considered for future research in this field. Firstly, probiotics could be used in an adequate amount for a longer duration to achieve a higher success rate as studied from literature. Secondly, we did not evaluate the $\mathrm{pH}$ of the plaque in our study, which could have affected the results with the use of Recaldent as its action is also dependent on the $\mathrm{pH}$.

\section{CONCLUSIONS}

From the results obtained in the present study, it can be summarized that:

- Streptococcus mutans colonies around the brackets one week after placement of brackets. (control group) were found to be statistically non-significant in all three study groups.

- Streptococcus mutans colonies around the brackets after 30 days post use of Fluoride toothpaste was reduced by $44.5 \%$, after 30 days post use of Probiotic curd was reduced by $0.86 \%$, and after 30 days post use of Recaldent was reduced by $41.8 \%$.

Based on our findings, it can be concluded that regular use of fluoride toothpaste and Recaldent during orthodontic treatment can effectively reduce WSLs and enhance tooth remineralization. To achieve this, patient education and compliance are of utmost importance.

\section{CONFLICT OF INTEREST}

The authors declare no conflict of interest. 


\section{REFERENCES}

1. Mizrahi E. Enamel demineralization following orthodontic treatment. Am J Orthod. 1982;82(1):62-7.

2. Chatterjee R, Kleinberg I. Effect of orthodontic band placement on the chemical composition of human incisor tooth plaque. Arch Oral Biol. 1979;24(2):97-100.

3. Willmot D. White spot lesions after orthodontic treatment. Semin Orthod 2008;14(3):209-19.

4. Bishara SE, Ostby AW. White spot lesions: formation, prevention, and treatment. Semin Orthod 2008;14(3):174-82.

5. Sudjalim TR, Woods MG, Manton DJ. Prevention of white spot lesions in orthodontic practice: a contemporary review. Aust Dent J. 2006;51(4):284-9.

6. Caglar E, Kargul B, Tanboga I. Bacteriotherapy and probiotics' role on oral health. Oral Dis. 2005;11(3):131-7.

7. Anderson $\mathrm{MH}$, Shi W. A probiotic approach to caries management. Pediatr Dent 2006;28:151-3.

8. Zhu Y, Xiao L, Shen D, Hao Y. Competition between yogurt probiotics and periodontal pathogens in vitro. Acta Odontol Scand. 2010;68(5):261-8.

9. Flichy-Fernández AJ, Alegre-Domingo T, Peñarrocha-Oltra D, Peńarrocha-Diago M. Probiotic treatment in the oral cavity: An update. Med Oral Patol Oral Cir Bucal. 2010;15(5):677-80.

10. Cildir SK, Germec D, Sandalli N, Ozdemir FI, Arun T, Twetman S, Caglar E. Reduction of salivary mutans streptococci in orthodontic patients during daily consumption of yoghurt containing probiotic bacteria. Eur J Orthod. 2009;31(4):407-11.

11. Çaglar E, Sandalli N, Twetman S, Kavaloglu S, Ergeneli S, Selvi S. Effect of yogurt with Bifidobacterium DN-173 010 on salivary mutans streptococci and lactobacilli in young adults. Acta Odontol Scand. 2005;63(6):317-20.

12. Ono T, Hirota K, Nemoto K, Fernandez EJ, Ota F, Fukui K. Detection of Streptococcus mutans by PCR amplification of spaP gene. J Med Microbiol. 1994;41(4):231-5.

13. Igarashi T, Yamamoto A, Goto N. Direct detection of Streptococcus mutans in human dental plaque by polymerase chain reaction. Oral Microbiol Immunol. 1996;11(5):294-8.

14. van Pelt-Verkuil E, Van Belkum A, Hays JP. Principles and technical aspects of PCR amplification. Springer Science Business Media; 2008.

15. Chang HS, Walsh LJ, Freer TJ. Enamel demineralization during orthodontic treatment. Aetiology and prevention. Aust Dent J. 1997;42(5):322-7.

16. Dhawan R, Dhawan S. Role of probiotics on oral health: A randomized, double-blind, placebo-controlled study. J Interdiscip Dentistry. 2013;3(2):71

17. Ahn SJ, Lee SJ, Lim BS, Nahm DS. Quantitative determination of adhesion patterns of cariogenic streptococci to various orthodontic brackets. Am J Orthod Dentofacial Orthop 2007;132:815-21.

18. Geiger AM, Gorelick L, Gwinnett AJ, Griswold PG. The effect of a fluoride program on white spot formation during orthodontic treatment. Am J Orthod Dentofacial Orthop1988; 94:123-8.

19. Loesche WJ, Rowan J, Straffon LH, Loos PJ. Association of Streptococcus mutans with Human Dental Decay. Infect Immun. 1975;11(6):1252-60.
20. Lindquist B, Emilson C. Distribution and prevalence of mutans streptococci in the human dentition. J Dent Res 1990; 69(5):1160-1166.

21. Hamilton IR. Biochemical effects of fluoride on oral bacteria. J Dent Res.1990;69(Spec Iss):660-667.

22. Luoma H. Phosphorus Translocation between enamel and streptococcus mutans in the presence of sucrose and fluoride with observations on the acid phosphatase of s mutans. Caries Res.1980;14:248-257.

23. Luoma $\mathrm{H}$ and Tuompo $\mathrm{H}$. The relationship between sugar metabolism and potassium translocation by caries-inducing streptococci and the inhibitory role of fluoride. Arch Oral Biol. 1975 Nov;20(11):749-55

24. Stratemann MW, Shannon IL. Control of decalcification in orthodontic patients by daily self-administered application of a water-free 0.4 per cent stannous fluoride gel. Am J Orthod. 1974 Sep;66(3):273-9.

25. Gorelick L, Geiger AM, Gwinnett AJ. Incidence of white spot formation after bonding and banding. Am J Orthod 1982;81:93-98.

26. O'reilly MM, Featherstone JDB. Demineralization and remineralization around orthodontic appliances: an in vivo study. Am J Orthod Dentofacial Orthop 1987;92: 33-40.

27. Øgaard B, Rølla G, Arends J, Ten Cate JM. Orthodontic appliances and enamel demineralization Part 2. Prevention and treatment of lesions. Am J Orthod Dentofacial Orthop1988;94:123-8.

28. Artun J, Brobakken BO. Prevalence of carious white spots after orthodontic Treatment with multibonded appliances. Eur J Orthod. 1986;8(4):229-34.

29. Reynolds EC. Calcium phosphate-based remineralization systems: scientific evidence. Aust Dent J 2008;53:268-273.

30. Cross KJ, Huq NL, Palamara JE, Perich JW, Reynolds EC. Physicochemical characterization of casein phosphopeptide-amorphous calcium phosphate nanocomplexes. J Biol Chem. 2005;280(15):15362-9.

31. Walsh LJ. Contemporary technologies for remineralisation therapies: A review. International Dentistry SA.2009;11(6):6-16.

32. Manton DJ, Walker GD, Cai F, Cochrane NJ, Shen P, Reynolds EC. Remineralization of enamel subsurface lesions in situ by the use of three commercially available sugar-free gums. Int J Paediatr Dent. 2008;18(4):284-90.

33. Rose RK. Effects of an anticariogenic casein phosphopeptide on calcium diffusion in Streptococcal model dental plaques, Arch Oral Biol 2000;45:569-575.

34. Keçik D, Cehreli SB, Şar Ç, Ünver B. Effect of acidulated phosphate fluoride and casein phosphopeptide amorphous calcium phosphate application on shear bond strength of orthodontic brackets. Angle Orthod. Jan;78(1):129-33.

35. Jagat B, Chachra S. Probiotics - Their role in prevention of dental caries. J Oral Health Comm Dent. 2010;4(3):78-82.

36. Reynolds EC, Cai F, Cochrane NJ, Shen P, Walker GD, Morgan MV, Reynolds C. Fluoride and casein phosphopeptide-amorphous calcium phosphate. J Dent Res 2008; 87(4):344-8.

37. Kumar VL, Itthagarun A, King NM. The effect of casein phosphopeptideamorphous calcium phosphate on remineralization of artificial caries-like lesions: an in vitro study. Aust Dent J. 2008;53(1):34-40. 